\title{
An Applied Study for the Restoration and Conservation of a Museum-Stored Colored Stone Coffin Lid from the Late Period
}

\author{
Shaimaa Sayed Mohamed El-Sayed \\ Conservation Department, Faculty of Archaeology, Luxor University, Egypt \\ Email: Egyptianconservators2013@gmail.com
}

\begin{abstract}
:
The colored stone coffin lids are exposed to many different deterioration factors, whether in the burial or exposure environment. In the burial environment, these colored coffin lids are subjected to the pressure of soil sediments, which leads to their being crushed into parts, especially since the case study is made of limestone. In the soil, caused by the presence of ground water, which leads to the crystallization of salts and the growth of microorganisms. Also, false excavation of these colored stone coffins lids and their transfer from equilibrium in the burial environment to the exposure environment leads to exposing to other pressures and may lead to irreversible damage and loss of color, as the temperature difference in the exposure environment and burial environment will lead to fissures and cracks as well. Crystallization of salts in the case of high temperature, as well as the difference in relative humidity levels, will lead to the dissolution of the color-bonding material and the dissolution of the air pollution gases, which leads to the formation of acids that interact with the material of these stone coffins lids to form water-soluble compounds, which leads in the end to the loss and deterioration of them. The selected object of study is a colored stone coffin lid no. 1939, broken into several parts of limestone (about 13 parts), dated to the Late Period and saved in Atifyah museum store Ministry of Tourism and Antiquities- Giza - Egypt, samples were taken from limestone, red and black pigments and examined by optical microscope, polarizing microscope and Scanning Electron Microscope (SEM) also analyzed by X-Ray Diffraction (XRD). The restoration processes are summarized in cleaning, consolidation, assembling and loss-compensation for the selected colored stone coffin lid.
\end{abstract}

Keywords:

museum - stored; colored stone coffin lid; late period; restoration; conservation

\section{Introduction}

The selected colored stone coffin is located in Atifyah museum store, which is administratively affiliated to the Giza Governorate, 80 kilometers south of Cairo on the eastern bank of the Nile(Abdel Kader,R.R.,\& El-Sayed,S.S.M., 2017), where Atifyah was the capital of the twenty-second region of Upper Egypt (Mission égypto-française d'Atfih .,2008).

\subsection{Archaeological Documentation of the Selected Colored Stone Coffin Lid:}

- The coffin lid number in the archaeological record: 1939.

- The number of the coffin lid when it was discovered at the excavation site: 17.-

- Date of registration in the archaeological record: 2/6/1982-

- The discoverer's name: Mohamed Radwan Ahmed (Director of Helwan Antiquities Zone during this period).

Excavation area: Kotsika.

Current saving place: Atifyah museum store. 
1.2 Archaeological Description in the Archaeological Record of Atifyah Museum Store:

The coffin lid is broken into several parts of limestone (about 13 parts) dating back to the late period, the face is painted in red and black, the chest is painted with an eagle in red, and under it the hands are shown together in red, and underneath it are hieroglyphic writings, the base of the coffin is absent.

Material: Limestone.

Coloring method: direct coloring on limestone.

\subsection{Photographic Documentation:}

- The coffin lid was recorded photographically before, during and after the restoration to identify the various deterioration factors, which are as follows:

- Mud and dust dirt.

- Weakness of limestone and colored layer.

- The colored stone coffin lid was shattered into several parts as a result of its exposure to many mechanical pressures in the burial environment, which necessitated the assembly processes-figure (1:4).

\subsection{Restoration Processes and Materials: a. Mechanical and Chemical Cleaning:}

The cleaning process is one of the necessary processes in the treatment process, which is chosen according to the monument's material and as its condition in terms of strength and weakness permits. This process must be applied very carefully because if applied negligently and without care it may completely destroy the monument (Richardson, B.A., 1995).

Paulo Mora considers that mechanical cleaning is one of the best ways to remove dust, light surface layers and salts, simple tools are used in the cleaning process, such as brushes of both soft and coarse types, scalpels, scrubbers, chisels and manual sticks, brushes are used with different softnesses in removing dust and various erasers are used as vinyl erasers in removing dirt adhering to the surface, the success of this process depends on the manual skill of the restorer (Alessandrini, G.,etal.,2003).

Chemical cleaning means using organic solvents, acids and alkali in removing the remaining dirt and dust from the mechanical cleaning process, organic solvents are commonly used like: Acetone, Toluene and Ethyl alcohol.

\section{b. Consolidation Processes:}

Consolidation processes are considered one of the most important steps in the conservation plan but before its application, the porosity of the stone, size of the pores and their distribution must be determined and accordingly the degree of concentration of the consolidants will be chosen as well as the appropriate application method .For the success of the consolidation process there must be a strong penetration of the consolidant into the stone to achieve the desired goal of the it (Ginell,W., and Coffman,R.,1998).

Consolidants are divided into organic, inorganic and nanomaterials, inorganic consolidants like : Calcium hydroxide (lime water), Sodium and potassium silicates but organic materials like : Acrylic and epoxy resins, silicon based materials, the nanomaterials are some consolidants in nanoparticles size ,as example : Nano silica and Nano lime water. 


\section{c. Assembling Process:}

This process is considered also one of the important processes in the restoration in which the separated or partially broken parts are returned partially or completely to their original places, thus achieving the original form of the monument by using an appropriate adhesive material, and many tests are performed on it to ensure its suitability for use and this process can be considered one consolidation methods because they return strength and durability to the monument, this process requires a trained, experienced, skilled restorer (ElSayed,S.S.M.,2012).

Adhesive materials like: epoxy, polyester, araldite (1092 as example), polyvinyl acetate and primal AC33, stainless steel bars can also be used in the assembling of heavy and large separated parts beside using the adhesives.

\section{d. Loss - Compensation Process (Completion):}

Loss - compensation process is extremely important, from a technical or aesthetic point of view to the monument, in order to preserve it. The importance of completion is limited to the following:

1. Elimination of weaknesses in the monument.

2. Finding pivots or Fulcrum points in the case that they do not exist or are part of them.

3. Completing the shape of the monument in general to achieve its aesthetic aspect.

- There are two directions in the loss - compensation process:

A trend that believes that the monument should be left without completion as long as it is not necessary, which is sometimes preferred .And another trend sees the completion of the monument in general, which is the most correct thing in other times, as the state of the monument calls for that.

- General rules for loss - compensation or completion process:

1. It is not permissible to complete the monument without the presence of guide or index points, or to rely on scientific or historical evidence confirmed, and this is for the purpose of conserving and preserving it in the absence of guidance points and in very special cases.

2. Replacements of missing parts must integrate harmoniously with the whole, but at the same time must be distinguishable from the original so that restoration does not falsify the artistic or historic evidence (Venice charter 1964- Article 12).

3. Completion with the same materials that were used in the past in making monuments such as supplementing the stone with natural stone powder and synthetic resins, and in special circumstances it can be done with another similar material, provided that it meets all the specifications of the restoration materials like: microballoon.

4. The completion material should be irreversible, stable against ultraviolet rays, be chemically inert, and not change color over time.

5. The material should be similar in its physical properties with the monument such as appearance, water absorption, elasticity, etc., and that its application does not result in the presence of salts or any mechanical pressures(Wold,J.G.,and Uricheck,S.,1998).

6. When using new materials or formulations taken from published scientific research, experiments and tests must be done to verify their validity before applying them.

7. Upon exposure to the completion of the sculptural works, all the sculptural effects of the sculptural pieces must be preserved, including dimensions, proportions, surface texture and color.

8. In addition to archaeological documentation, executive documentation of all stages and steps of the application program must be completed in terms of detailed work steps, materials used, components and mixing ratios, and published scientific reports so that the 
restorers can have archival material that helps them to analyze, compare, form opinion and the appropriate restoration direction.

9. The completion must be done in such a way that it does not obliterate or change the nature of the monument, and that the restorer respects the additions or modifications that have been added over the ages.

10. The necessity of having some differences consistent with the monument of the place of completion or loss-compensation like : difference in color, surface level and texture.

11. The restorer in charge of the completion must deal with and interact with the monument and the missing part with the sense of the committed artist through the spirit and culture of the Age of monument.

\section{Research Methods}

Samples were taken from the colored stone coffin lid material and pigments to determine their components and to study the damage they suffered through analysis by X-Ray Diffraction (XRD). The samples also examined by optical microscope to study the surface , polarizing microscope to identify the components and deterioration aspects and the Scanning Electron Microscope (SEM) to study the surface condition with different magnification power-figure $(5: 10)$.

\subsection{Restoration Processes of the Colored Stone Coffin Lid No.1939: a. Cleaning Process:}

Firstly, the mechanical cleaning of the dust and mud dirt was carried out by different soft brushes (Doehne,E., \& Price , A.C., 2010). As for the remaining mud dirt in the noncolored areas of the coffin lid, they were cleaned with distilled water, while the mud dirt on the surface of the colored layer was cleaned with ethyl alcohol 70\% (Abdel Kader, R.R.,\& ElSayed,S.S.M., 2019), where it was found that the colored layer in the coffin is sensitive to water- figure (11:15).

\section{b. Consolidation Processes:}

Consolidation was done by brushing the colored coffin, which suffers from the weakness of the material of manufacture (limestone) as well as the weakness of the color layer by using Wacker $(\mathrm{OH}$ 100) diluted with ethyl alcohol at a concentration of 3\% (Abdel Kader,R.R.,etal, 2019) in 4 cycles of consolidation(waiting for every layer to be dry before the other layer's application) with intensive care when consolidating the colored area due to its weakness(Malaga, K., etal)-figure (16:19).

\section{c. Assembling Process:}

The assembling process of the limestone pieces forming the colored stone coffin lid was done by bars of stainless iron (Riccardelli,C.,2014), with the use of a mixture of Araldite 1092 and limestone powder to fix these bars, and the components of the colored limestone coffin lid were assembled-figure (20:23).

\section{d. Loss - Compensation Process:}

The missing parts of the colored coffin lid were completed by a mixture of Primal AC33 and limestone powder with differentiation and homogeneity between the completed part and the original parts of the coffin lid (El-Sayed,S.S.M.,etal, 2020)- figure (24:27). 


\subsection{Conservation Recommendations}

It's recommended to save the restored coffin lid (case study) in a storing environment free from air pollution acids, salts, dust and microorganisms in a temperature degree 18-20 $\circ \mathrm{C}$ and relative humidity $45-50 \%$.

\section{Results and Discussion}

- It is found through analysis by X-Ray Diffraction (XRD) that limestone sample is composed of Calcite (54.5\%), Zinc Oxide (11.28\%), Dolomite (7.19\%), Feroxyhite $(15.3 \%)$ and Wuestite $(11.66 \%)$, it was noticed that iron oxides percentage in the sample is very high (Feroxyhite $(15.3 \%)+$ Wuestite $(11.66 \%)=26.96 \%$, and thus exposing it to dissolution in the event of high relative humidity, which means that the limestone is damaged and weak. Also, samples of red and black pigments were analyzed by X-Ray Diffraction, and it became clear that the source of the red pigment is Hematite Fe2O3, and the black pigment comes from carbon granules $(\mathrm{C})$.

- The surface of the limestone sample was examined by light microscope, and the presence of iron oxides was evident on the surface of the sample.

- The limestone sample was also examined by a polarizing microscope to study the inner tissue of the sample, as well as to identify the mineral components inside it and the presence of calcite and iron oxides within the sample components.

- Finally, the sample was examined by a Scanning Electron Microscope (SEM) (1000 x), where it was found that the inner texture of the limestone surface was weak in the colored stone coffin lid.

\section{Conclusion}

The colored stone coffins lids, especially the limestone ones, are severely damaged in the burial environment because limestone is considered a soft stone (Calcite hardness is 3 according to Mohs hardness scale), the most important of which is the pressure of soil sediments such as the case study, which means the need to preserve this ancient and rare cultural heritage as this colored coffin lid dates back to the late period of the ancient Egyptian civilization and thus its scarcity Remaining traces of this era.

Through the examination and analysis of the material for making the colored stone coffin lid, it was found that the limestone is very weak and contains a large percentage of iron oxides, which means that these oxides dissolve in the presence of high relative humidity and consequently severe damage. Therefore, it was necessary to intervene in the restoration of this colored stone coffin lid from cleaning, consolidation, assembly and loss - compensation works taking into account preserving the color layer and not losing it, and thus preserving this precious ancient cultural heritage.

\section{Acknowledgment}

- Dr/ Rabea Radi Abdel Kader Sayed - Researcher and General manager of monuments restoration authority - Ministry of Tourism and Antiquities - Egypt.

- Mr/ Mohamed Abdel Ghany - Conservator in Atifyah museum store - Ministry of Tourism and Antiquities - Egypt. 


\section{References}

Abdel Kader,R.R.,\& El-Sayed,S.S.M.,(2017), The Thermal Weathering Of Limestone In Atfiyah's Sarabium Archaeological Site From The Late Period - An Investigative Study, IJIET - Special Issue on EGE 2017, International Journal of Innovations in Engineering and Technology (IJIET),PP:15-20.

Abdel Kader, R.R.,\& El-Sayed,S.S.M.,(2019), Conservation of Archaeological Limestone False Doors - Applied on a Door No. 1755 at Atfiyah Museum Store Egypt,Vol.4,No.1, Arabic Language, Literature \& Culture, Science Publishing group, USA, PP:16-20.

Abdel Kader,R.R.,etal,(2019), Study The Severe Effects of Iron Compounds Presenting in Sandstone on the Deterioration of Wall Paintings of Archaeological Tombs in Bahariya Oasis - Egypt, Vol.1, No.3, Budapest International Research in Exact Sciences (BirEx) Journal,PP:5-13.

Alessandrini, G.,etal.,(2003), on the cleaning of deteriorated stone minerals, in conservation of stone and other materials, first edition,F\&Fnspon,London, P:503.

Doehne,E., \& Price , A.C.,(2010), Stone Conservation(An Overview of Current Research), second edition, the Getty Conservation Institute, California, USA,P:40.

El-Sayed,S.S.M.,(2012), Study of the burial environment effect on the deterioration of the excavated Alabaster Objects, Restoration and Conservation methods applied on some chosen objects", MSc thesis, Conservation department, faculty of Archaeology , Cairo University, Giza, Egypt.

El-Sayed,S.S.M.,etal,(2020), Desert Environment Effect on the Deterioration of Ancient Building Materials in Archaeological Buildings (El- Bagawat Tombs, El - Kharga Oasis as an Example),Vol.2,No.2,Britain International of Exact Sciences (BIoEx) Journal,PP:476-485.

Ginell, W., and Coffman, R.,(1998), epoxy - resins consolidated stone: appearance change on aging, in studies in conservation,Vol.43,No.1, the international institute for conservation of historic and artistic works, London, P:247

Richardson, B.A.,(1995), remedial treatment of buildings, second edition,Butterworth Heinemann, Great Britain,P:153.

Riccardelli,C.,etal,(2014), The Treatment of Tullio Lombardo's Adam: A New Approach to the Conservation of Monumental Marble Sculpture, in Metropolitan Museum Journal, vol.49, Metropolitan Museum of Art, New York, PP:49-116.

Malaga, K., etal, Consolidation of Gotland sand stone,Swedish national testing and research institute, Sweden,P:4.

Mission égypto-française d'Atfih (2008), Atfih, la nécropole des vaches sacrées (mission 2008), Institut d' Egyptologie Francois Daumas, Universite Paul Valery, France.

Wold, J.G., \&Sari Uricheck, S.,(1998), loss compensation methods for stone, journal of the American institute for conservation, Vol.37,No.1,Article7, P:89. 


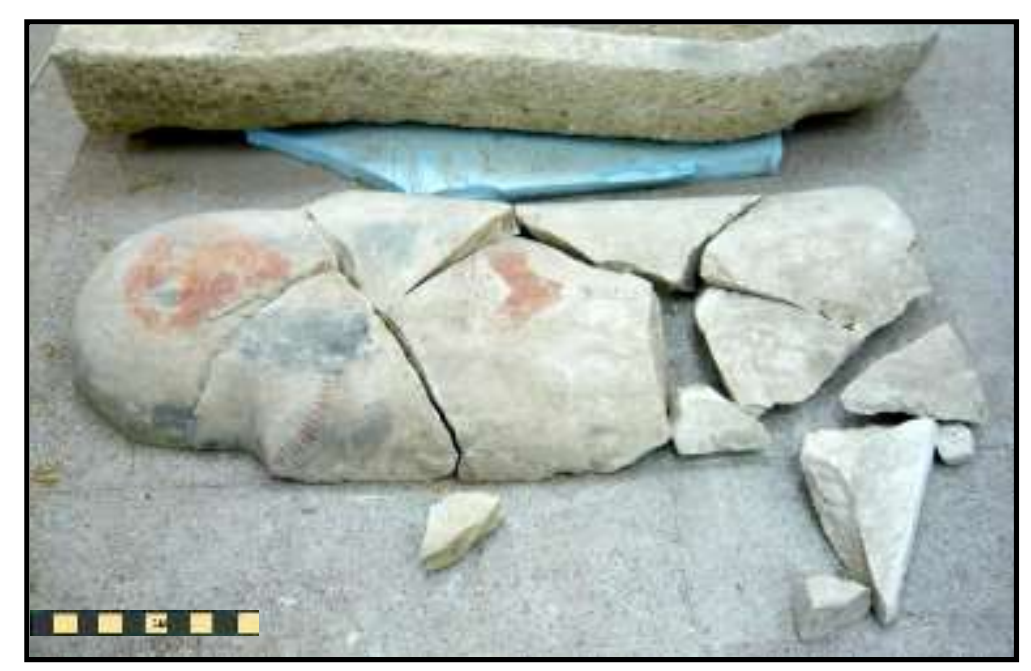

Figure 1. The colored stone coffin lid before restoration processes

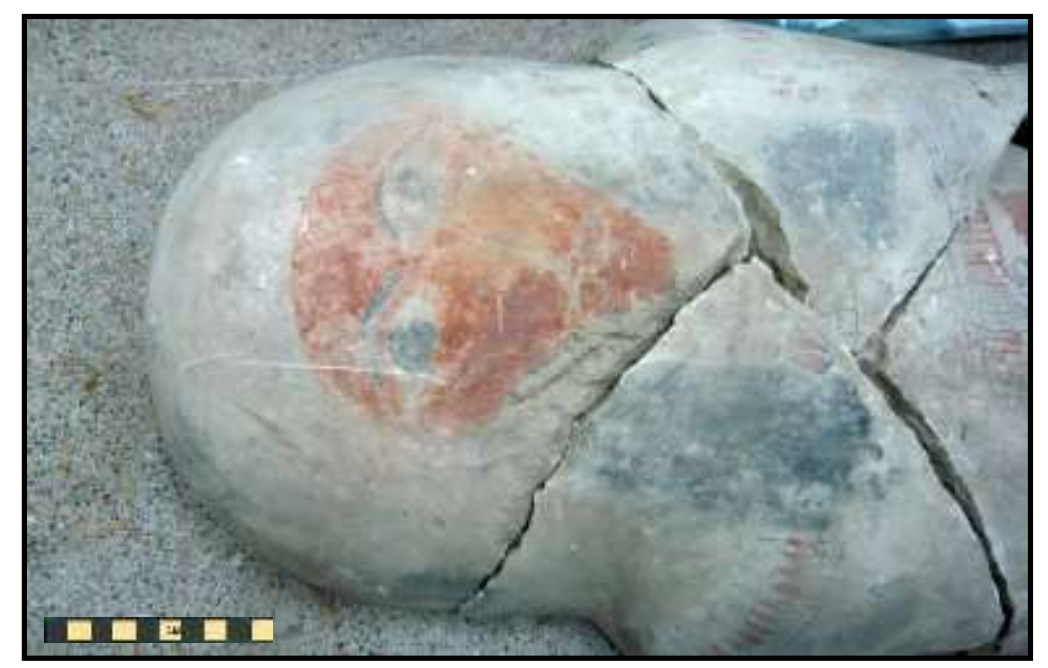

Figure 2. Shows the weakness of the colored layer

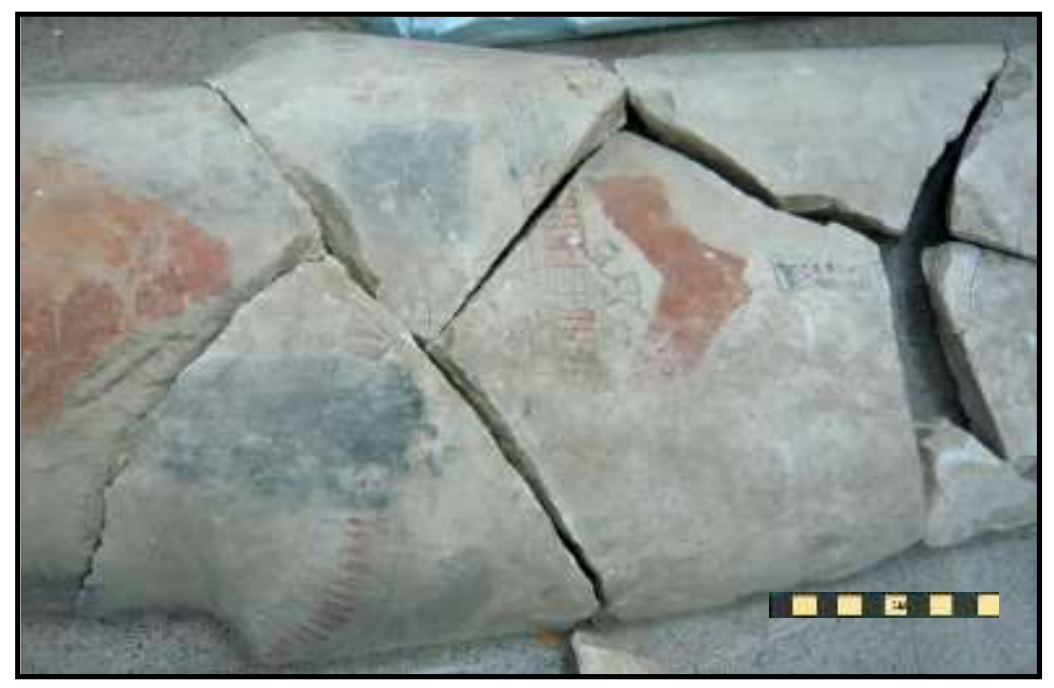

Figure 3. Shows that the colored stone coffin lid has been broken into several parts 


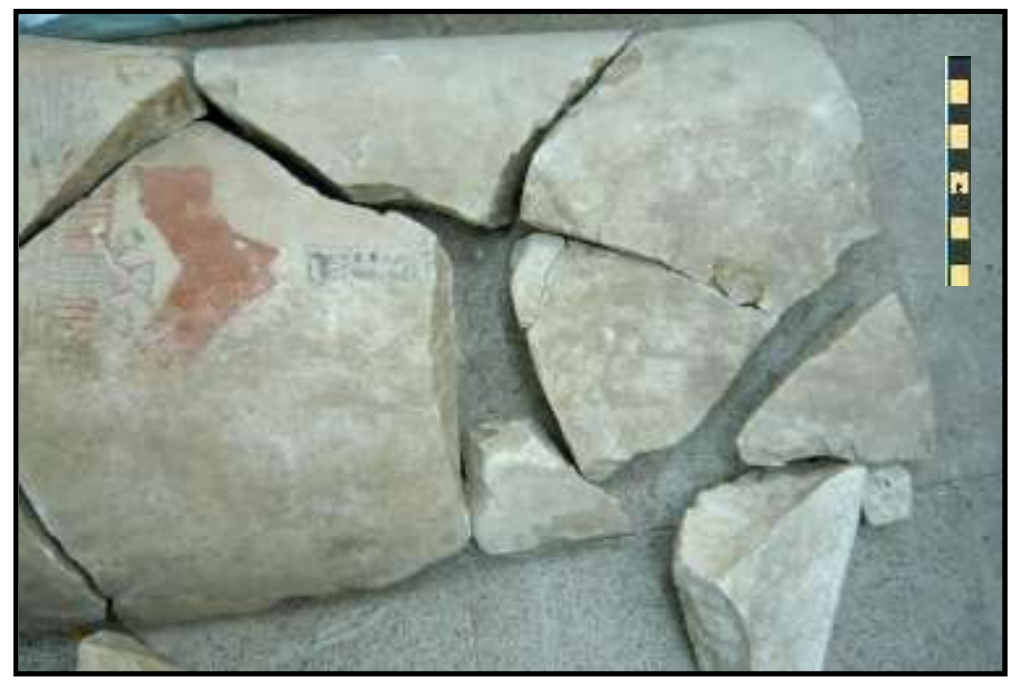

Figure 4. Shows mud and dust dirt on the surface

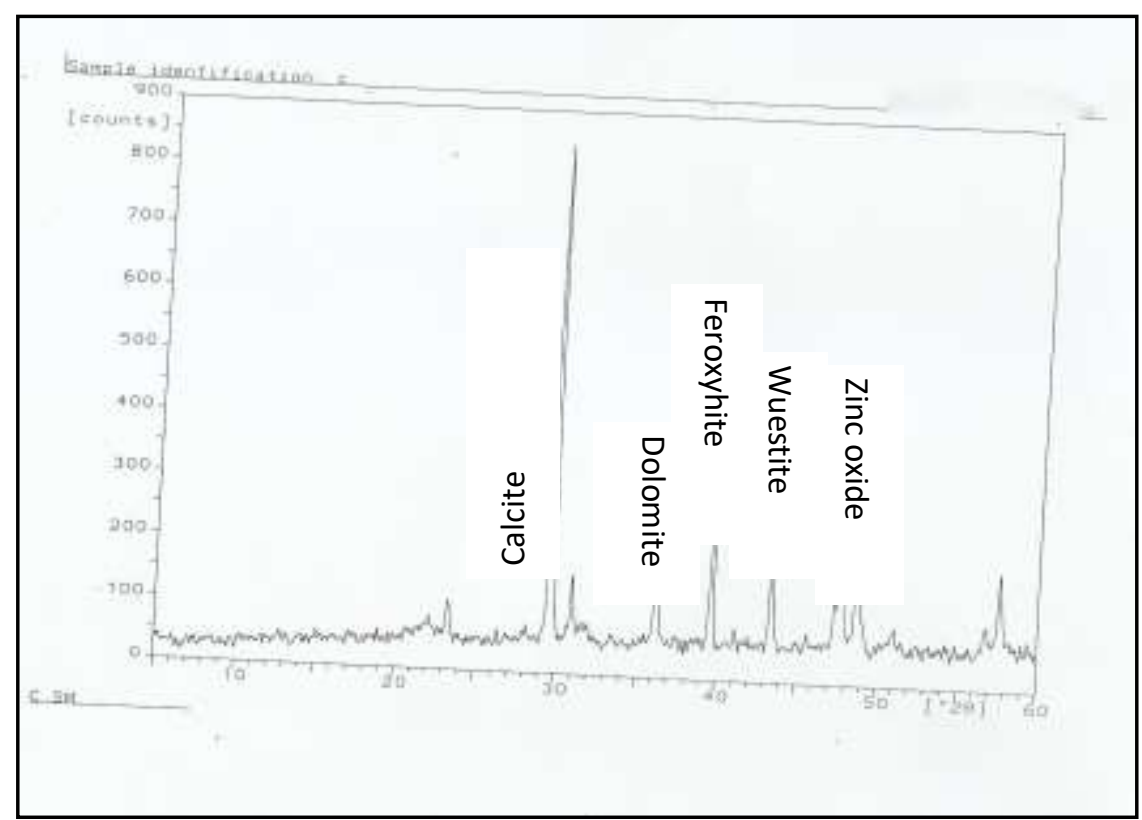

Figure 5. XRD pattern for limestone's sample

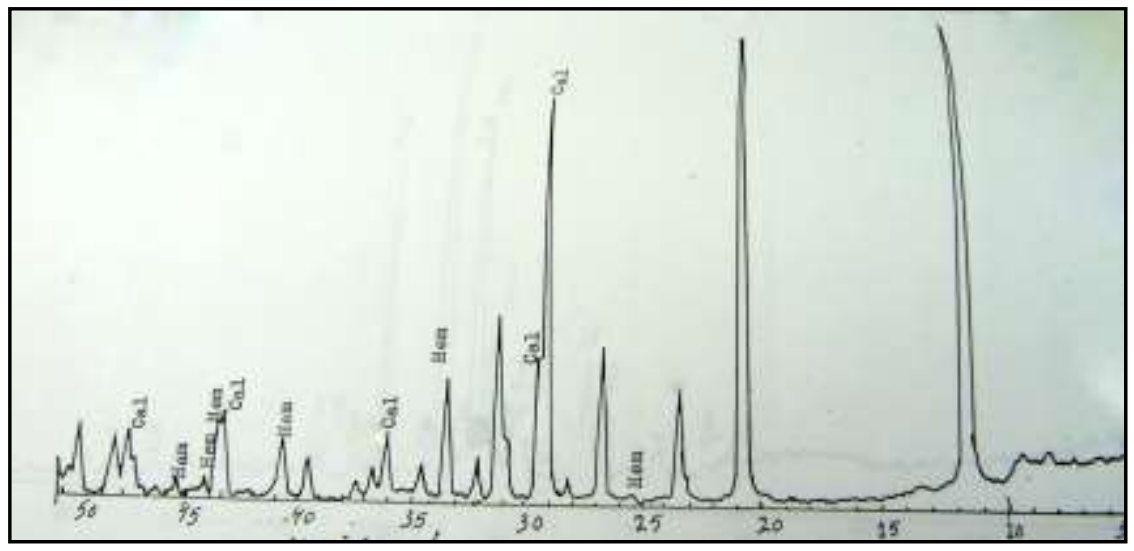

Figure 6. XRD pattern for the red pigment 


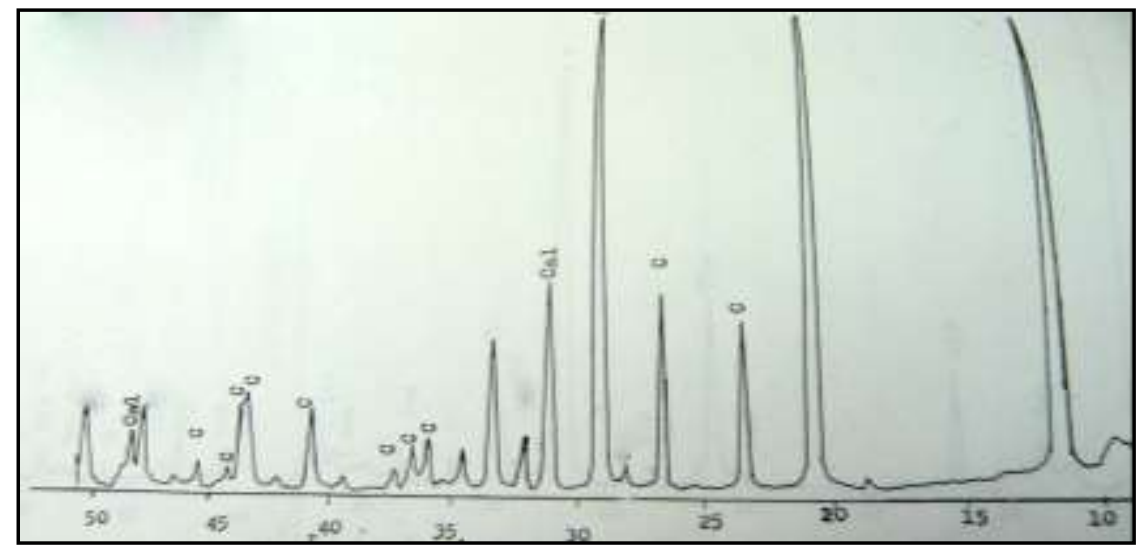

Figure 7. XRD pattern for the black pigment

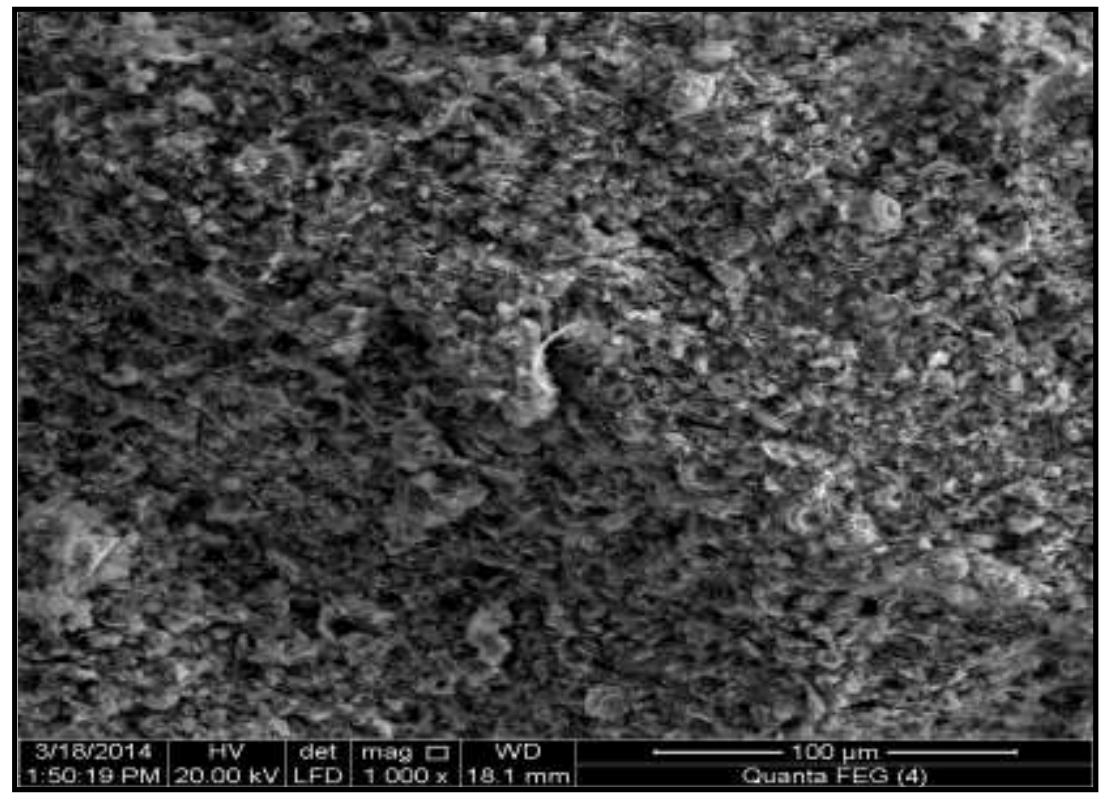

Figure 8. Shows the weakness of limestone surface (SEM examination - x1000)

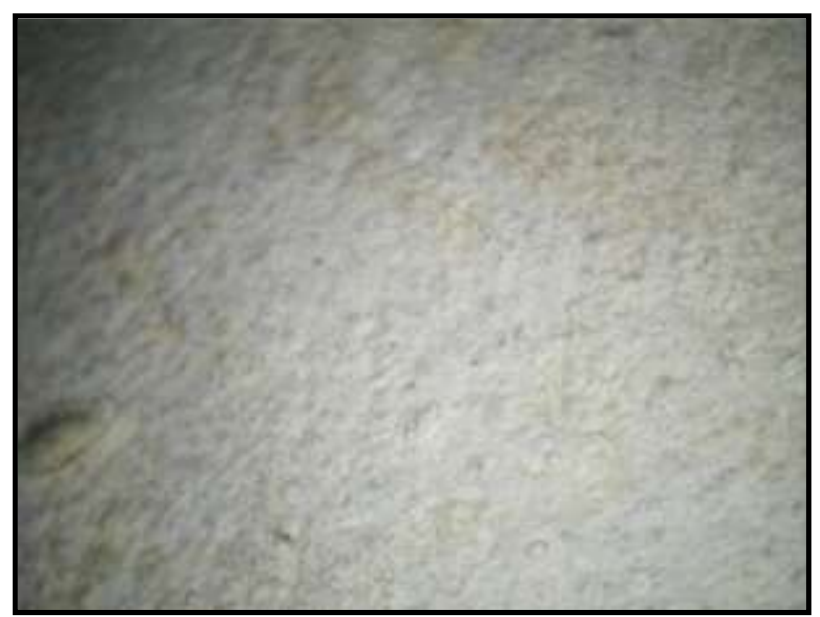

Figure 9. Shows the light microscope examination of the limestone's sample, it's obvious the brown spots due to the high percentage of iron oxides 


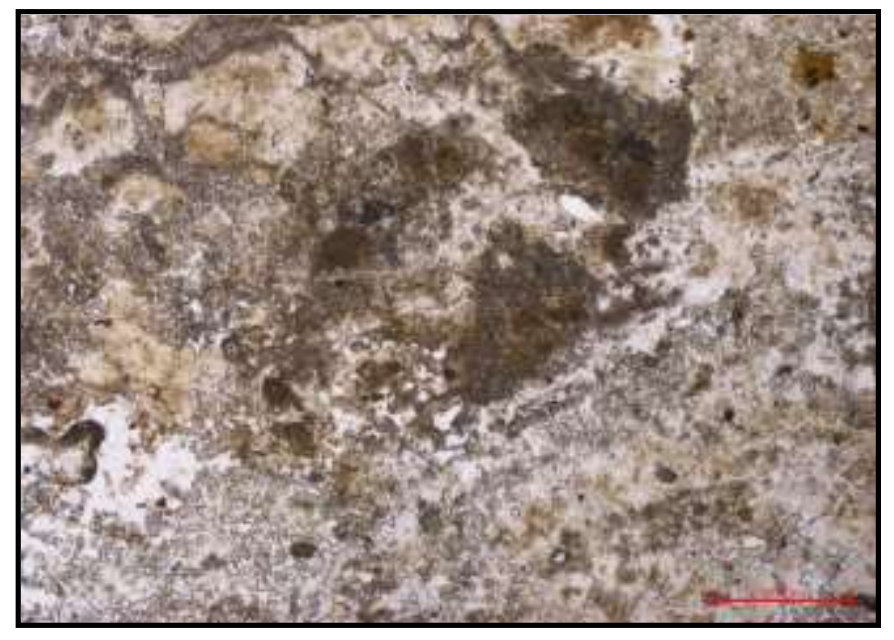

Figure 10. The polarizing examination of the limestone's sample

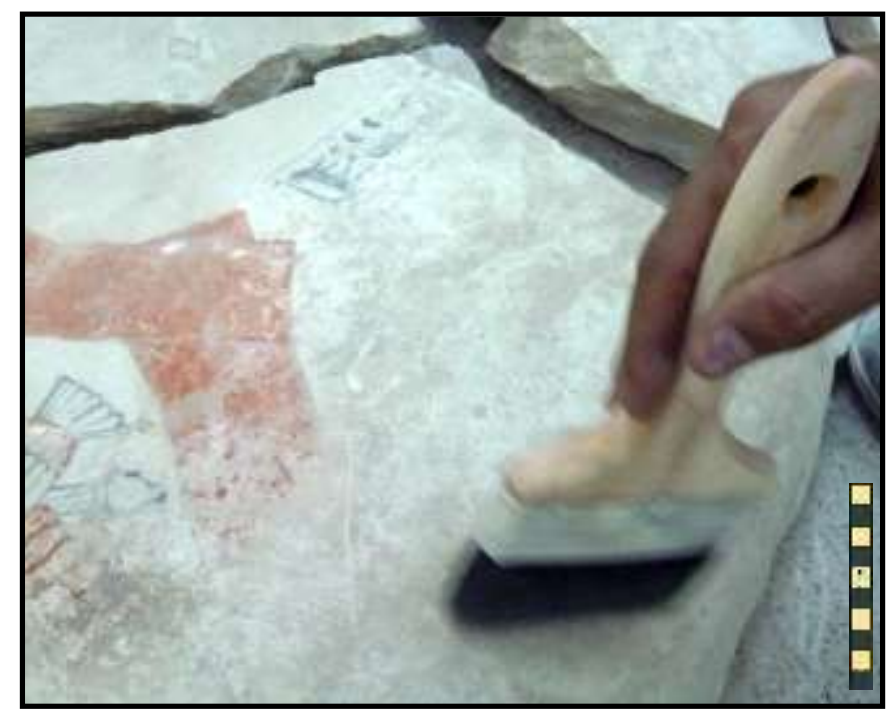

Figure 11. The cleaning of dust from the colored area by a soft brush

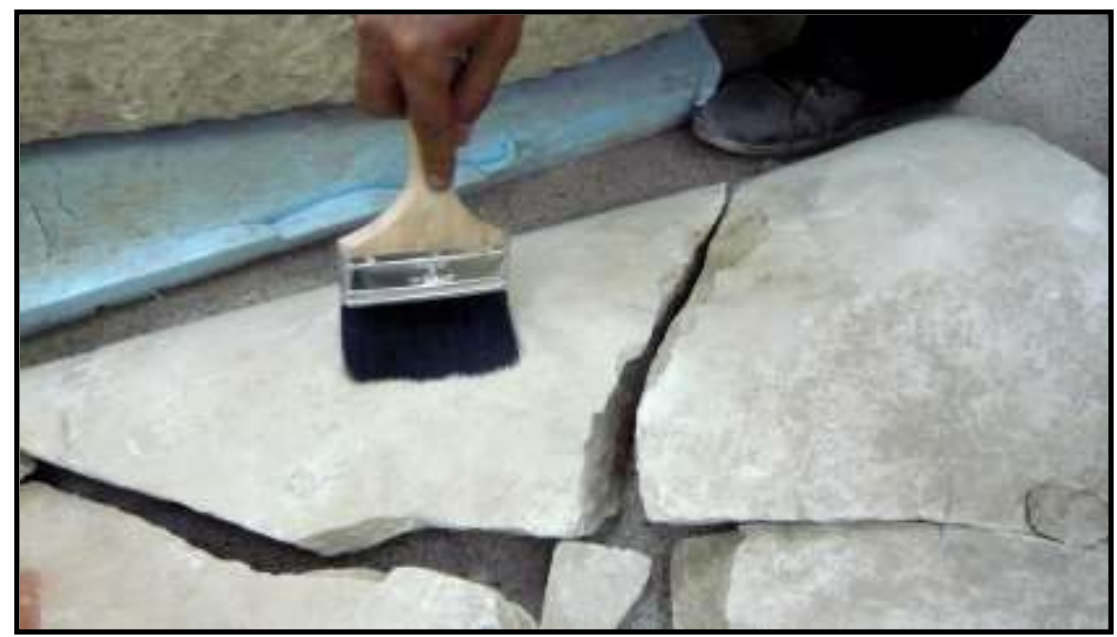

Figure 12. The cleaning of mud dirt by a soft brush 


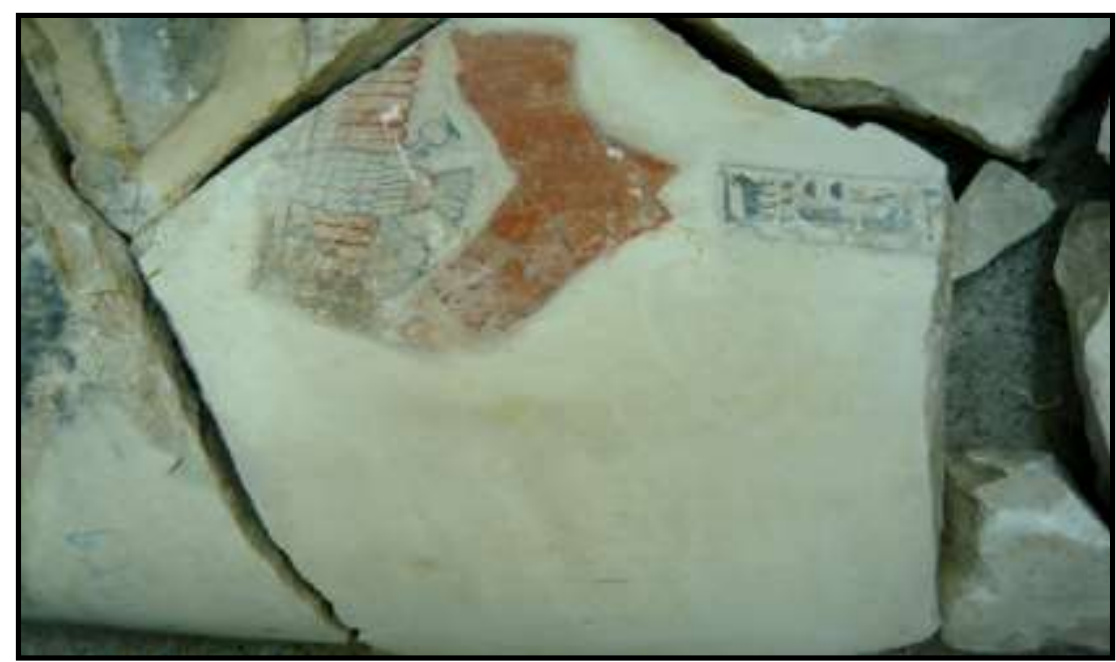

Figure 13. The cleaning of the remaining dirt by distilled water (non- colored area)

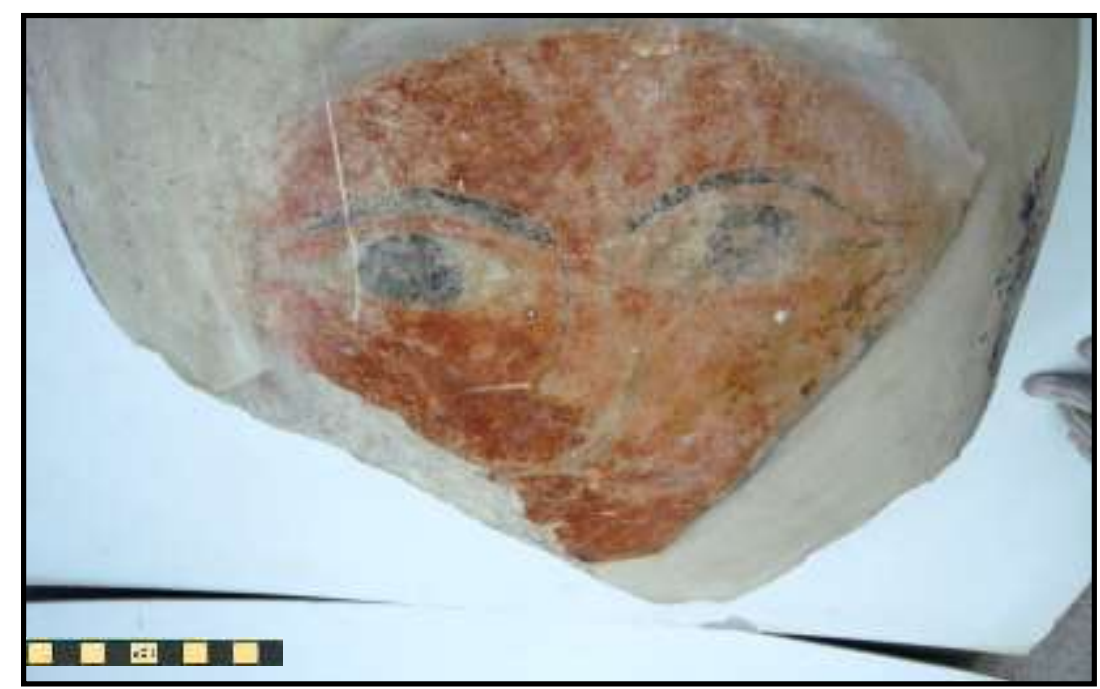

Figure 14. The cleaning of the remaining dirt by ethyl alcohol 70\% (colored area- water sensitive)

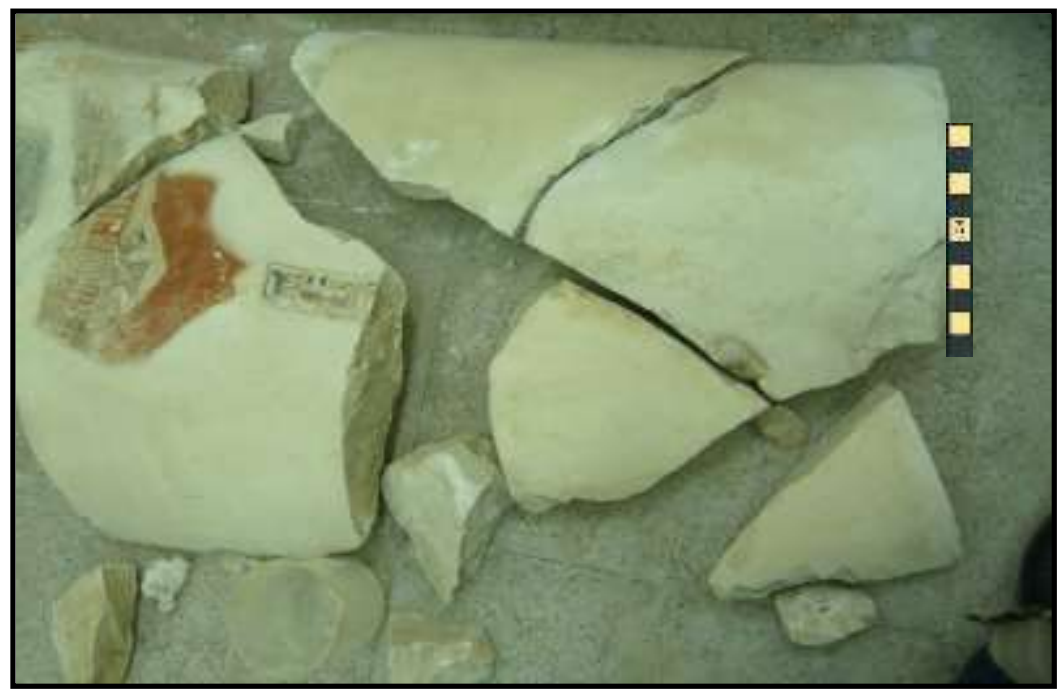

Figure 15. The colored stone coffin lid parts after cleaning processes 


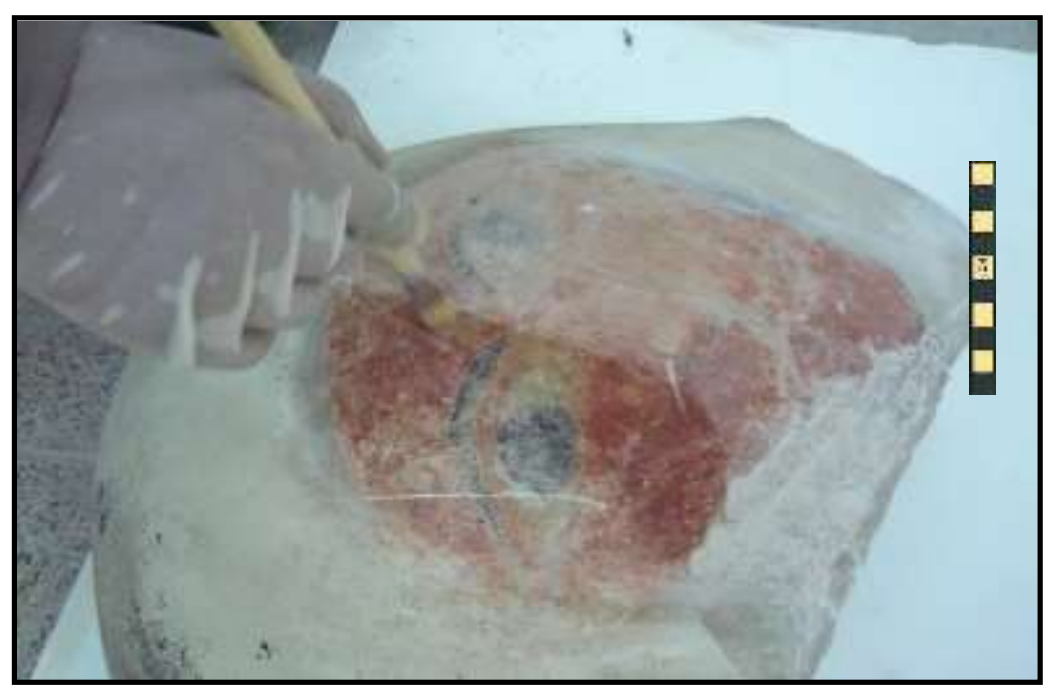

Figure 16. The consolidation of the colored area by brush

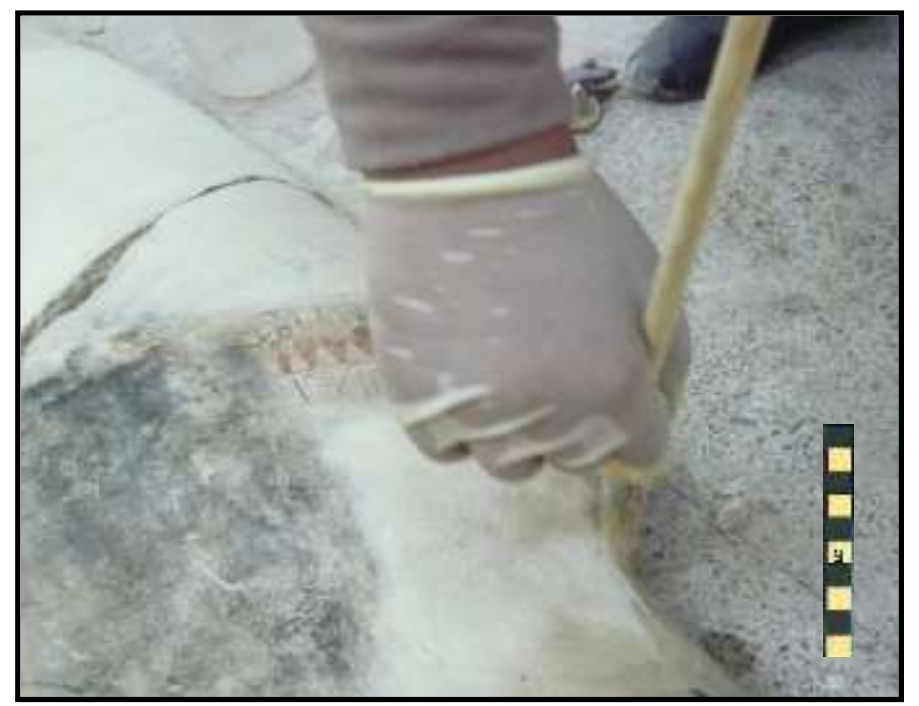

Figure 17. The consolidation with Wacker (OH 100)

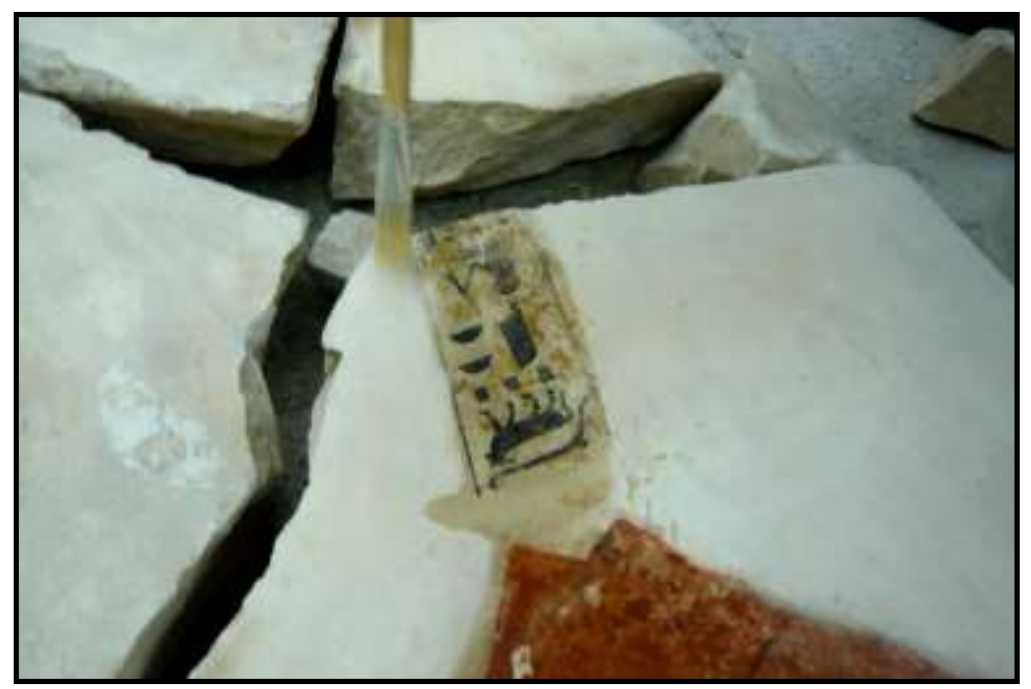

Figure 18. The hieroglyphic writings become clear after cleaning and consolidation processes 


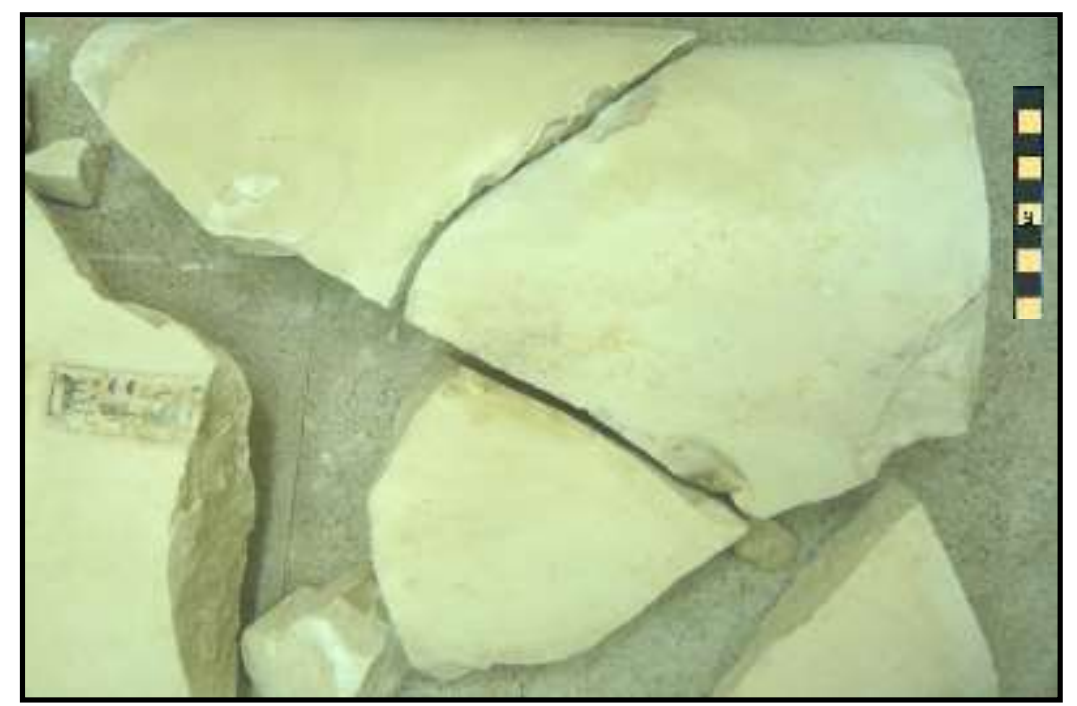

Figure 19. Parts of the coffin lid after cleaning and consolidation processes

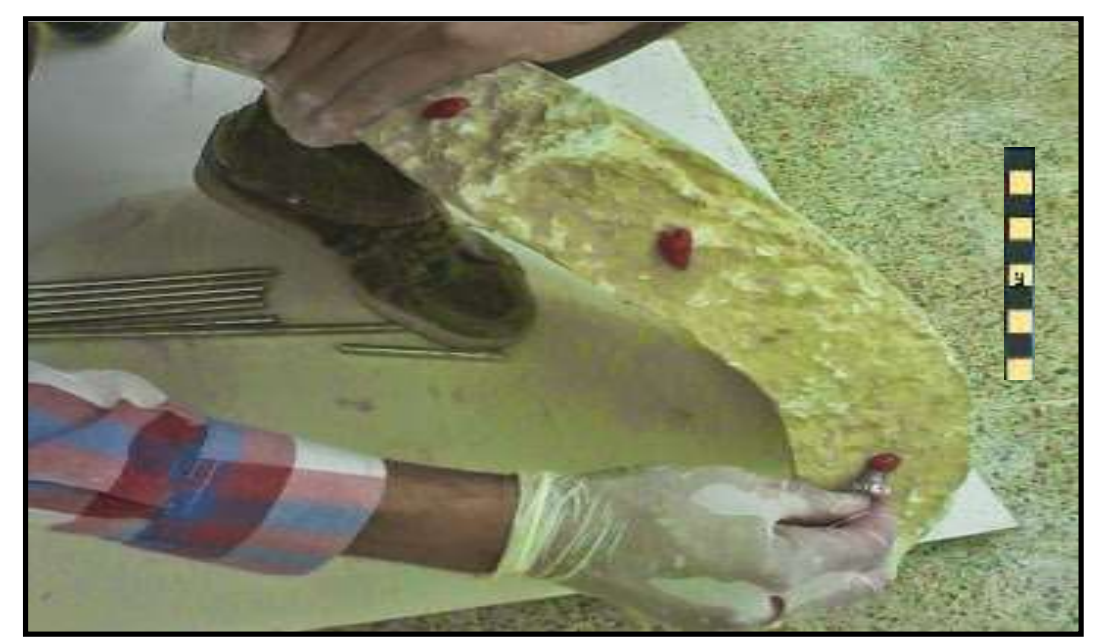

Figure 20. The determination of the assembling points

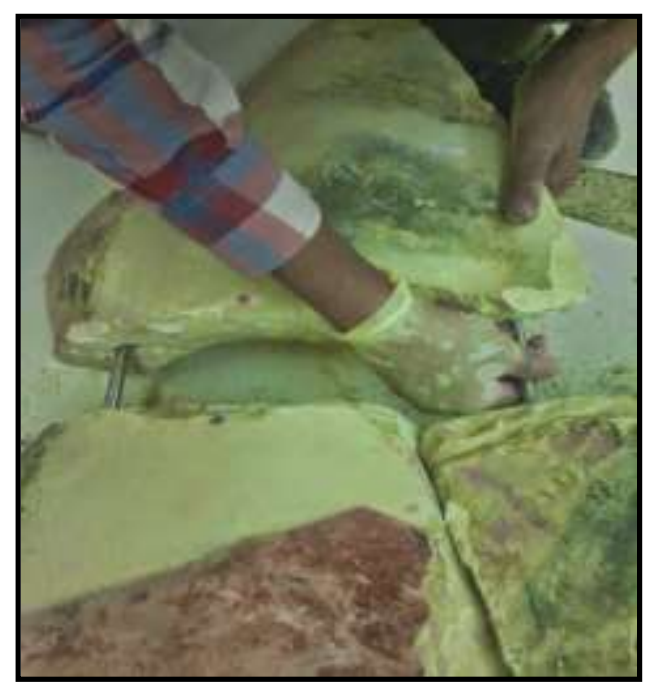

Figure 21. The stainless steel iron bars installation 


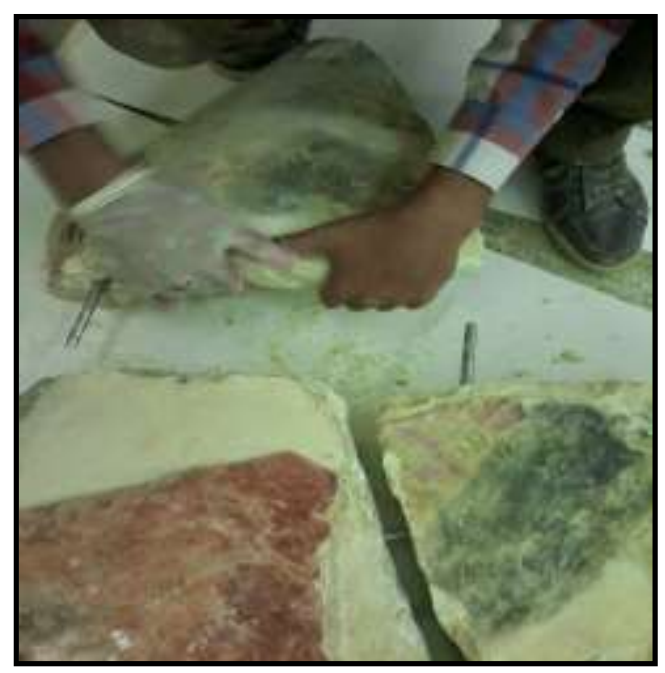

Figure 22. Another figure shows the assembling process using stainless steel iron bars and Araldite 1092

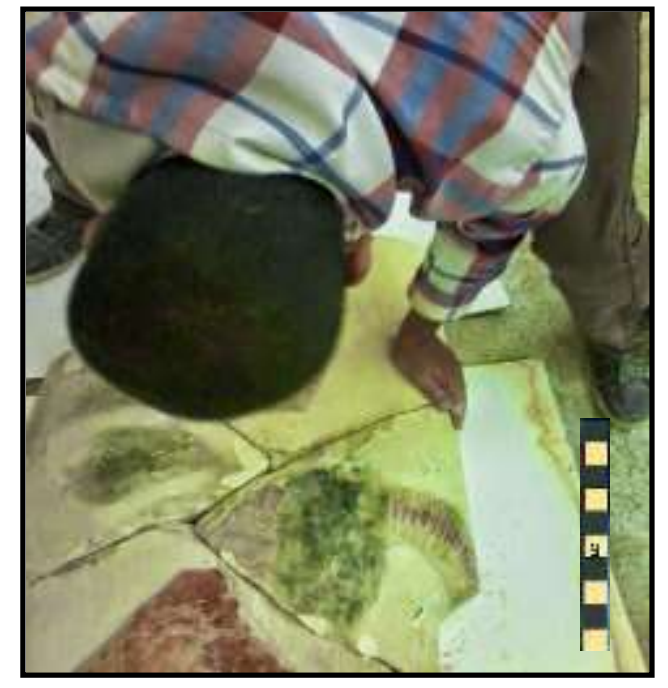

Figure 23. Assembling process of the coffin lid separated parts
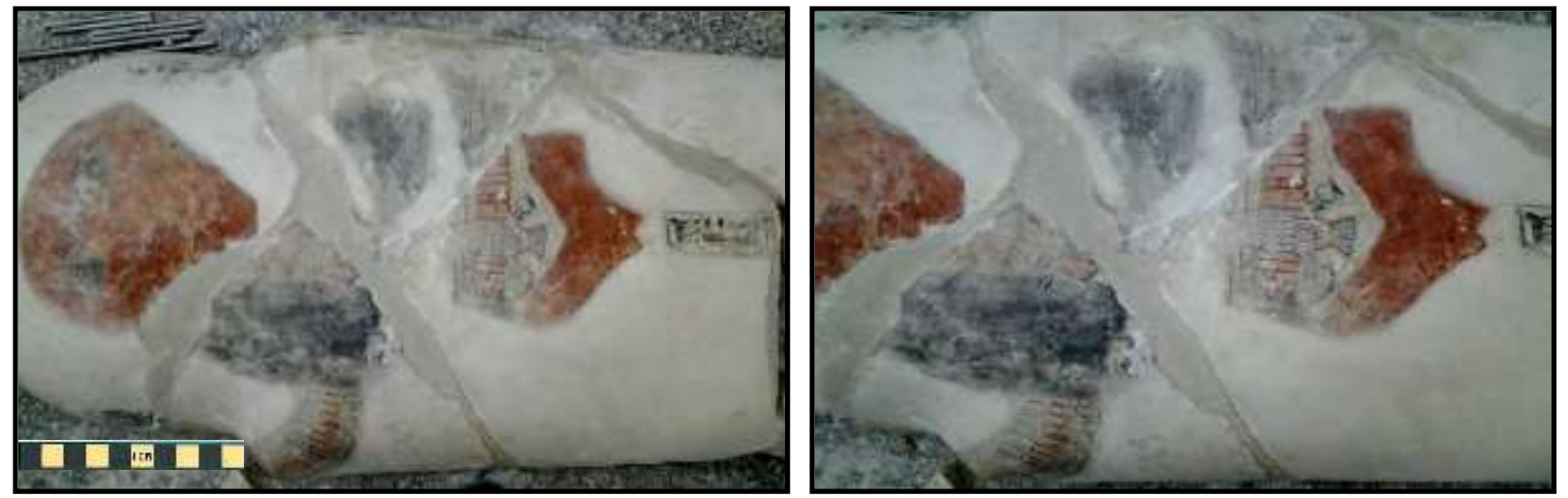

Figure 24-25. Loss- compensation process of the coffin lid 


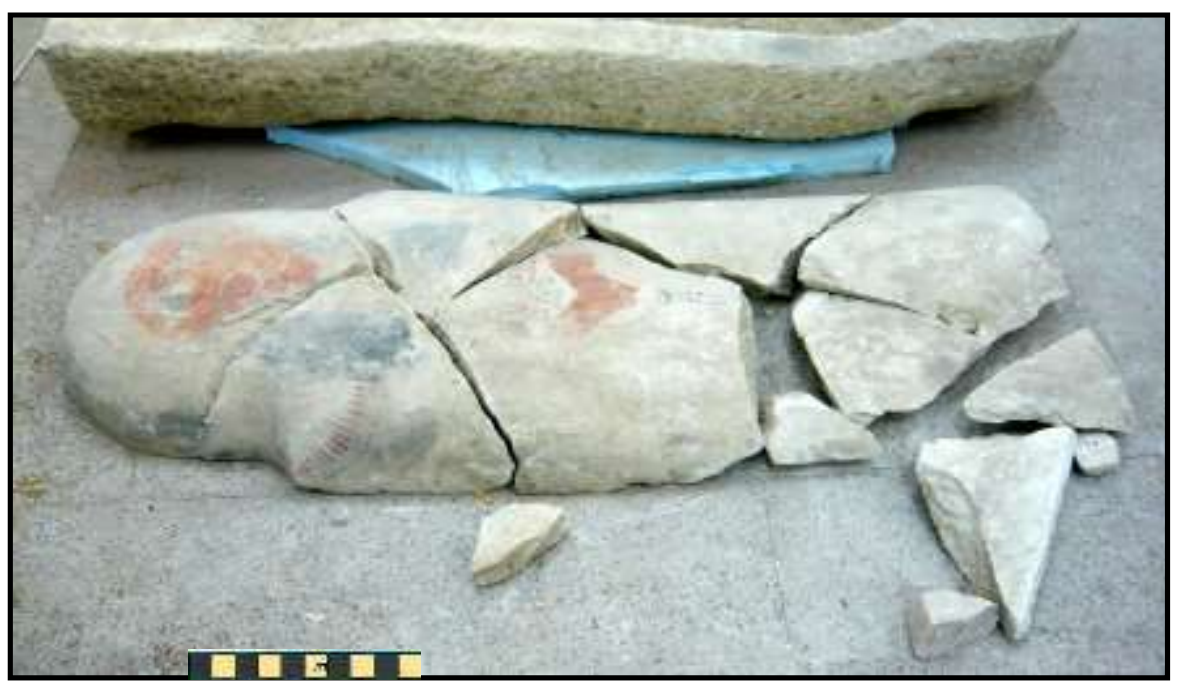

Figure 26. The coffin lid before restoration process

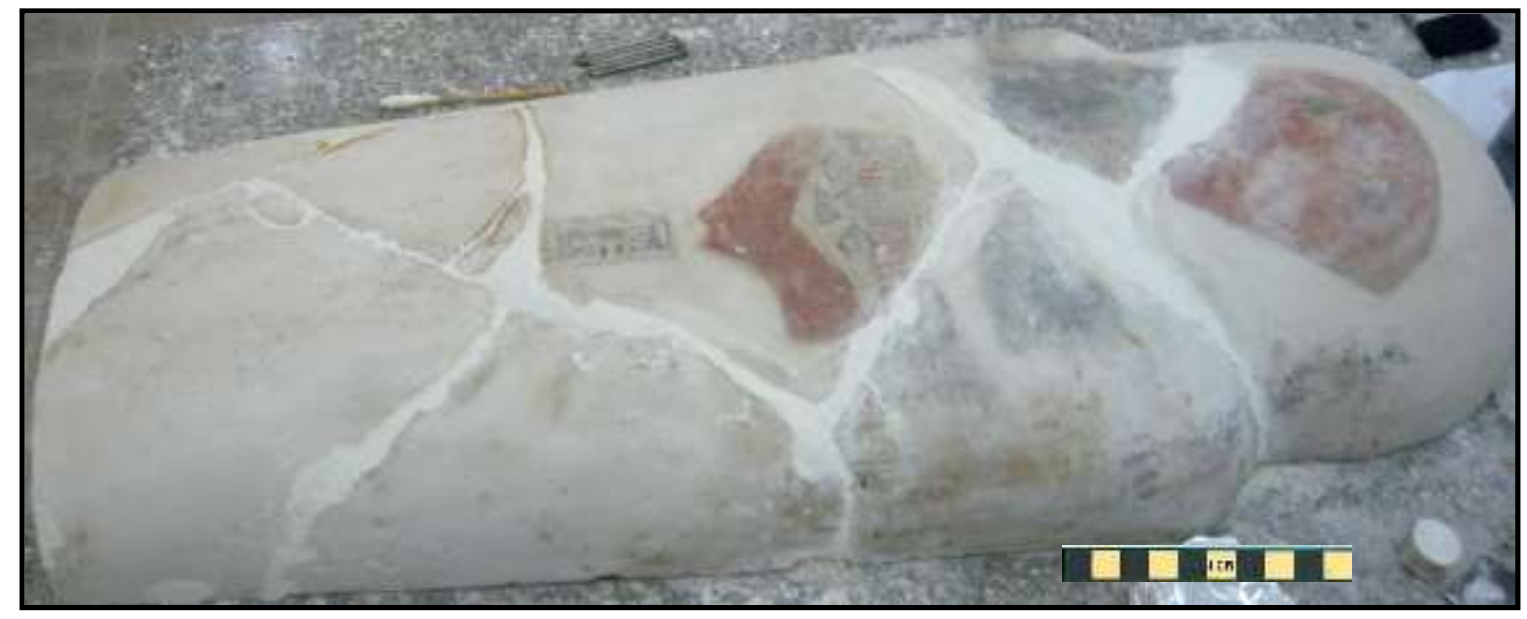

Figure 27. The coffin lid after restoration process 